\title{
Photoresist with Anti-Cracked and Fine Profile for High Speed Gold Bump Plating
}

\author{
Koji SAITO*, Hiroshi KOMANO and Toshimi AOYAMA
}

Received January 17, 1995 ; Accepted March 8, 1995

\begin{abstract}
The anti-cracking and the profile of thick layer positive photoresist, for high speed gold bump plating in the surface mounting technology, has been improved by selection of molecular weight of novolack resin and developing method.

The conventional resist pattern lines were cracked frequently at the plating temperature under $60^{\circ} \mathrm{C}$, on the other hand, these new resin with higher molecular weight resin were protected from being cracked and hold fine profiles at $70^{\circ} \mathrm{C}$.

Frequent replacement of developer during puddle development shorten the developing time to $70 \%$ and made fine pattern profile with straight vertical side walls.

With this improvement, the square gold bumps $20 \times 20 \mu \mathrm{m}$ with $20 \mu \mathrm{m}$ in thickness has been sufficiently formed in the halftime of the conventional process.
\end{abstract}

\section{INTRODUCTION}

With increasing demend for down-sized electronic equipment, the development of finesize LSIs (Large scale integrated circuits) with a higher integration is making rapid progress. More specifically, a further advanced thin-film surface mounting technology (SMT) for attaching LSI chips on the inner lead or the like of a tape carrier is required. Accordingly, Tape Automated Bonding (TAB) and Flip-chip attachment technology have been attracting much attention1,2). The SMTs require, however, that a bump be formed between the bonding pad of the LSI and the inner lead. The bump can be fabricated on the bonding pad of an LSI chip or on the lead of $\mathrm{TAB}$ by metal plating, and the fabrication thereof is believed to be the key technology for the achievement of a successful fine pitch SMT. Because $I / 0$ in SMT are increasing and a density of $100-\mu \mathrm{m}$ pitch or higher is attained, conventional mushroomshaped bumps are no longer effective in the mounting technology. Bumps with vertical side

Tokyo Ohka Kogyo Co., Ltd. (1590 Tabata, Samukawa-cho, Kanagawa 253-01, Japan )

Key Words: Positive Photoresist, Surface Mounting Technology, Bump Plating. walls using thick-layer resists are therefore a requisite in the state-of-art-technology3). A resist for bump metal plating is characterized in that it should have: (1) sufficient thickness; (2) high sensitivity; (3) vertical side walls; (4) none generation of cracks on the metal plating; and (5) perfect stripping properties.

The present paper describes how the resist profile may be improved by modifying the development process, and how a change in molecular weight of the novolak resin influences the positive resist concerning the generation of cracks on the metal plating.

\section{EXPERIMENTAL}

\section{1 Positive photoresist}

A positive photoresist for bump plating is composed of naphthoquinone-1,2-diazide-5sulfonate (hereinafter simply referred to as "NQD-ester"), i.e., a photo-active compound, a novolak resin, and an adhesive promoter. Presumably, the resist characteristics concerning the stress upon plating can be improved by adjusting the molecular weight of the novolak resin in the photoresist. Thus, in the present study, pattern shapes and the like of a commercially available photoresist AR-900 (Tokyo Ohka Kogyo Co., Ltd.) for use in surface 
mounting were evaluated by changing the average molecular weight of novolak resin. More specifically, novolak resin samples having an average molecular weight of $16,900,25,000$, and 31,000 were used, and two more resin samples were prepared from a resin having an average molecular weight of 31,000 . In the latter two samples, low molecular weight fraction was partially removed to prepare resins having an average molecular weight of 36,300 and 38,200 .

\subsection{Development method}

As compared with the case of a resist for LSIs, a drop in the developing capability is expected to occur on the developer as a final stage is approached in the puddle development of a relatively thicker resist. Optimal conditions for the development were therefore studied using a development series of which the sequence was modified in such a manner that a fresh developer was introduced into the line during the development after removing the used one. Wafers were evaluated by observing the center and two points taken symmetrically at a distance of $3 \mathrm{~cm}$ from the center.

2.3 Condition of resist processing and plating

\subsubsection{Resist processing}

A gold film

which was vacuum deposited to a thickness of 1. $0 \mu \mathrm{m}$ on a $\mathrm{Si}$ wafer by sputtering was used as the substrate. Resist was coated on the substrate by a spinner and was baked at $100^{\circ} \mathrm{C}$ for $10 \mathrm{~min}$. Resulting thickness was obtained 20 $\mu \mathrm{m}$. Exposure was effected with a Nikon Stepper NSR-1505G4D, using an original window pattern as the mask. The exposed resist was treated by puddle development for $10 \mathrm{~min}$ using a developer, P-7G (Tokyo Ohka Kogyo Co., Ltd.), and rinsed in DI water for $60 \mathrm{~s}$, spin-dried.

\subsubsection{Metal plating \\ Metal plating was effected using Microfab Aul00 (Tanaka Kikinzoku} Kogyo K.K.) as the metal plating solution, while applying current, at a density of 0.4 $\mathrm{A} / \mathrm{dm}^{2}$ on Metal Plating Machine AU94-25M (Fujidenki Kogyosho K. K.). The metal plating was conducted over $60 \mathrm{~min}$, and temperatures of
$60,65,70$, and $75{ }^{\circ} \mathrm{C}$ were selected for the process. A gold plating of $20 \mu \mathrm{m}$ in thickness can be obtained in this manner.

\section{RESULT AND DISCUSSION}

3. 1 Influence of average molecular weight of novolak resin on the resistance against metal plating

Figure 1 shows SEM photos of a bump after plating a $20^{-} \mu \mathrm{m}$ resist pattern by a process effected at $70^{\circ} \mathrm{C}$ for $60 \mathrm{~min}$, while applying current, at a density of $0.4 \mathrm{~A} / \mathrm{dm}^{2}$, and one taken after the stripping of the resist. Three types of novolak resins, i.e., those with an average molecular weight of $31,000,36,300$, and 38,200 , were evaluated. Cracks were found to generate after plating in case that a photoresist containing a novolak resin with an average molecular weight of 31,000 was used. Table 1 shows the generation of cracks by the average molecular weight of novolak resin and the plating temperature. The cracks were found to generate in a large quantity as the molecular weight of the novolak resin was decreased. Reversely, fewer cracks were found to generate in the resist as the molecular weight of the novolak resin was increased. If resins with the same average molecular weight are used, more cracks tend to generate as the temperature of plating is elevated. In the case of a resin whose lower molecular portion has been removed, the larger the amount of such removal, the fewer the generation of crack. Figure 2 shows the relation between the size of bump formed by using a $60^{-} \mu \mathrm{m}$ window pattern and the temperature of the plating. The size of the bump thus formed tend to increase as the temperature of the plating is elevated. The change in size differs depending on the molecular weight of the novolak resin. The bump size is more affected by the temperature in the case that resin of lower molecular weights are used.

The softening point of novolak resin used in a positive photoresist is in the range of 


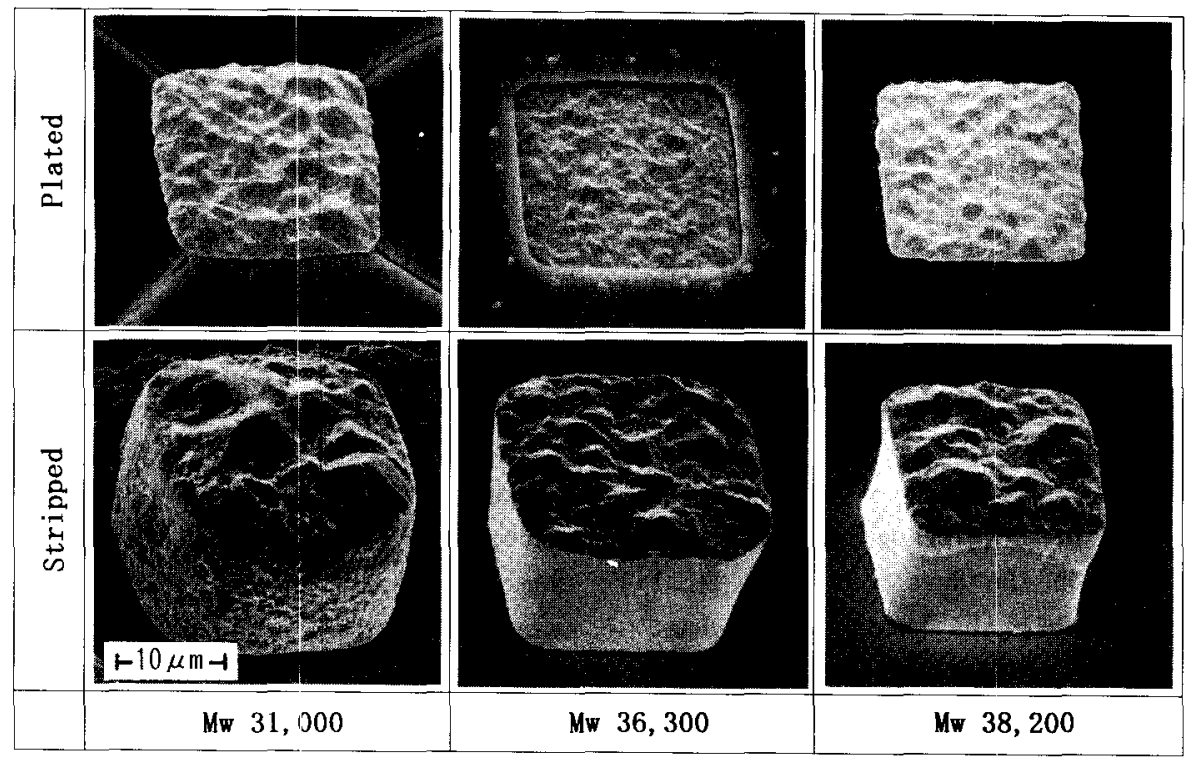

Fig. 1 Plated bump pattern; Current Density, $0.4 \mathrm{~A} / \mathrm{dm}^{2}$; Temperature, $70{ }^{\circ} \mathrm{C}$; Plating time, 60 min.

Table 1 Effect to resist crack after plating by molecular weight of novolak resin.

\begin{tabular}{|c|c|c|c|c|c|}
\hline M. W. & 16,900 & 25,000 & 31,000 & 36,300 & 38,200 \\
\hline 60 & $\times$ & $\triangle$ & $\bigcirc$ & 0 & 0 \\
\hline 65 & $\times$ & $\times$ & $\times$ & 0 & 0 \\
\hline 70 & $\times$ & $\times$ & $\times$ & $\triangle$ & 0 \\
\hline 75 & $\times$ & $\times$ & $\times$ & $\times$ & 0 \\
\hline
\end{tabular}

$\bigcirc$, Not generate; $\Delta$, Flewly generate; $x$, Generate.

from 80 to $90{ }^{\circ} \mathrm{C}$. However, the softening point is lower for the resin having lower molecular weights. An ester-based compound having a boiling point in the range of from 140 to $150^{\circ} \mathrm{C}$ is used as the solvent. Thus, in the case of a resist of $20 \mu \mathrm{m}$ in thickness, the solvent cannot be completely removed therefrom by baking. A resist film undergoes softening at a temperature of lower than the softening point of the novolak resin if a solvent remains in the resin. In the case that plating is effected at a temperature near the softening point of the resin, the resist may easily undergo deformation by the deposition of gold which exerts repulsive force onto the film, because the tensile strength of a resist $f i l m$ is low at a temperature in the vicinity of the softening point. The resist film thus deformed shrinks when it is cooled to room temperature after plating. It is believed that the cracks generate in the resist film according to this mechanism.

3.2 Improvement of resist profile by modifying the development method

Table 2 shows the difference in developability of a window pattern with varying development treatment. Figure 3 shows the micrographs of representative patterns obtained by changing the development treatment. The 
profile of the resulting window pattern can be classified into three types depending on the development treatment (Figure 4-1 to 4-3). Figure 4- 1 shows a vertical side wall. Figure 4-2 shows a side wall with tailing. Figure 4-3

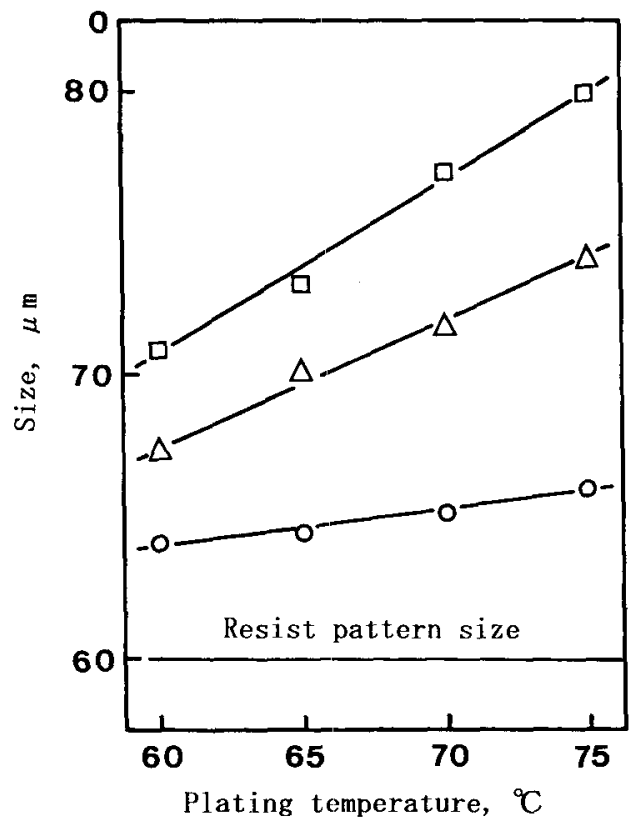

Fig. 2 Effect to plated pattern size by plating temperature. Molecular weight of novolak resin: $\square, 31,000 ; \triangle, 36,300$;

O, $38,200$. shows a partially developed case. It can be seen that window in micrograph No. 1 in Figure 3 is dark. Accordingly, it corresponds to a partially developed case (Figure 4-3). A defocused portion is observed in the outside of the window frame of the micrograph No. 4 in Figure 3. This case therefore corresponds to a side wall with tailing (Figure 4-2). A clearly distinguished window frame is observed in the micrograph No. 10 in Figure 3. Thus, this is a case which corresponds to a profile of the vertical side wall (Figure 4-1). In the case that a window pattern is repeatedly immersed into the developer for $4 \mathrm{~min}$ or longer within the development treatment, no profile with a vertical side wall can be obtained because tailing is found to generate. Even if the accumulated period of immersion is increased, a favorable profile can be obtained by increasing the repetitions of the immersion while decreasing the duration of each immersion. Furthermore, it is seen that side walls with tailing form more frequently on the peripheral portions as compared with the center portion of the wafer.

When an unexposed area of a positive photoresist is dipped into a developer, the low-molecular-weight fraction of the novolak resin, i.e., the fraction that is more readily dissolved into the developer, dissolves into

Table 2 Difference in developability with varying treatment.

\begin{tabular}{|c|c|c|c|c|c|}
\hline No. & Treatment method & $\begin{array}{l}\text { Total de } \\
\text { ing time, }\end{array}$ & $\begin{array}{l}\text { elop-Thickness } \\
\text { min. uniformity }\end{array}$ & $\begin{array}{l}\text { Resist } \\
\text { Profile }\end{array}$ & $\begin{array}{l}\text { Resist } \\
\text { remaining }\end{array}$ \\
\hline 1 & Standard development & 10 & $\mathrm{x}$ & 3 & $\bar{x}$ \\
\hline 2 & $5 \min \times 2$ & 10 & $x$ & 3 & $\bar{x}$ \\
\hline 3 & $3 \min \times 3$ & 9 & $x$ & 3 & $\triangle$ \\
\hline 4 & $4 \mathrm{~min}+4 \mathrm{~min}$ & 9 & $\bar{x}$ & $2-1$ & O \\
\hline 5 & $4 \min \times 2$ & 9 & $\underline{x}$ & 2 & O \\
\hline 6 & $4 \mathrm{~min}+\mathrm{H} 20 \mathrm{4min}$ & 8 & $\bar{x}$ & 2 & $\mathrm{O}$ \\
\hline 7 & $2 \min x \quad 3+1 \min \times 2$ & 8 & $\mathrm{O}$ & 1 & $\mathrm{O}$ \\
\hline 8 & $2 \min \times 4$ & 8 & $\mathrm{O}$ & 1 & $\mathrm{O}$ \\
\hline 9 & $2 \min +1 \min \times 5$ & 7 & $\mathrm{O}$ & 1 & $\mathrm{O}$ \\
\hline 10 & $1 \mathrm{~min} \times 6+0.5 \mathrm{~min}$ & 6.5 & $\mathrm{O}$ & 1 & $\mathrm{O}$ \\
\hline
\end{tabular}

Resist thickness uniformity in wafer; $O$, Uniform; $x$, Un-uniform.

Resist Profile:1, Vertical side wall; 2, Side wall with tailing;

3, Partially developed case. Resist remaining: $O$, Not remain;

$\triangle$, Fewly remain; $x$, remain. 


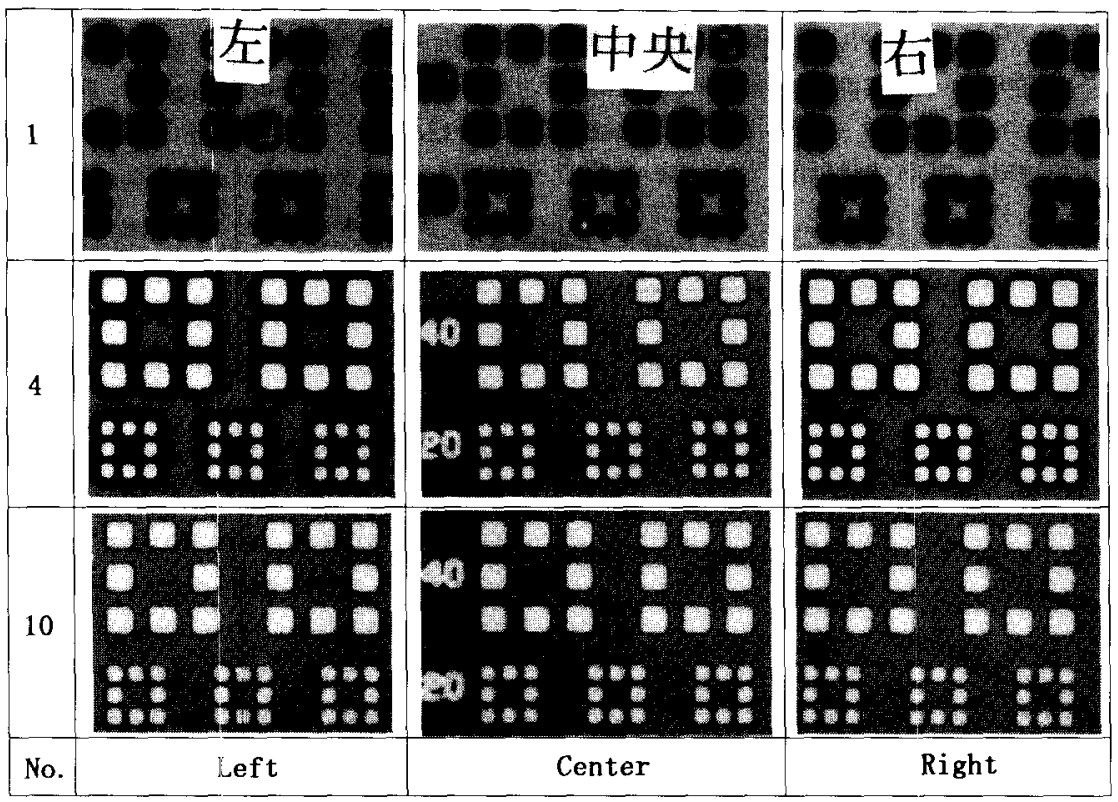

Fig. 3 Micrographs of reresentative patterns obtained by changing the development treatment.
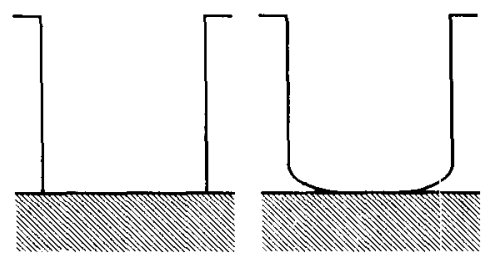

2

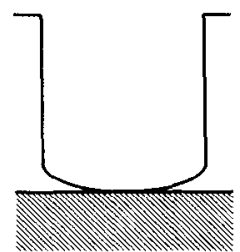

3
Fig. 4 Profile of developed window pattern. 1, Vertical side wal1; 2, Side wall with tailing; 3 , Partially developed case.

the developer to leave a dissolution inhibiting layer on the surface of the photoresist4). More specifically, the concentration of NQD ester and the high-molecular-weight portion of the novolak resin increases on the surface to develop a surface layer. On the other hand, the NAD group of the NQD ester decomposes to form a developer-soluble indencarboxylic acid on the exposed area. In the resist film of the exposed area, however, layers having a higher light intensity form periodically in turn with those having a lower light intensity at a period of $0.13 \mu \mathrm{m}$ from the surface to the substrate due to the standing waves which generate with the light being transmitted through the resist film. Figure 5 shows the distribution of light intensity in the resist film. NQD ester in the layer of high light intensity decomposes almost completely, while, that in a layer of low light intensity remains in a large quantity. During the development, NQD ester in the layer of low light intensity remains undissolved, and it tends to stay on the surface of the newlyappeared resist. Because the dissolution occurs from the surface layer in the development, NQD ester remains periodically in accordance with the period of the standing wave $\mathrm{e}^{5)}$. Thus, the concentration of NQD ester increases in this manner to generate a dissolution-inhibiting layer. It is presumed that this dissolution inhibiting layer causes partially 


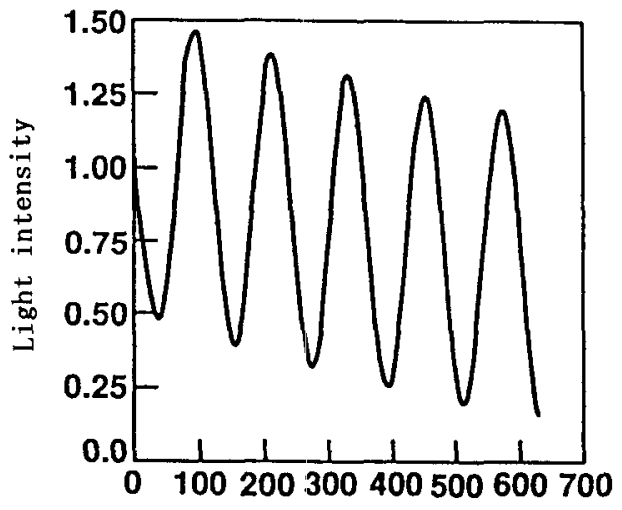

Depth from resist top, nm

Fig. 5 Light intensity distribution in the resist film by standing wave at exposure.

developed case. Figure 6 shows its schematic mechanism.

By shortening the time period necessary for each dipping while increasing the number of times the developer is replenished, NQD ester can be mechanically washed off. This method prevents $N Q D$ ester from remaining on the surface of the exposed area. A high rate of development can be maintained by thus suppressing the increase in the concentration of NQD ester on the surface of the resist. Presumably in this manner, a vertical profile can be obtained while reducing the accumulated duration of the development.

\section{3 High-speed gold plating}

The rate of plating can be accelerated by increasing the current density and by elevating the temperature of the plating bath. Under such preferred conditions for high-speed plating, however, cracks tend to generate more frequently on the photoresist due to the high temperature employed for the plating and due to the repulsive force exerted thereto by the metal deposits. Figure 7 shows a SEM photos of a bump plated at $70^{\circ} \mathrm{C}$ over $30 \mathrm{~min}$ at a density of $0.8 \mathrm{~A} / \mathrm{dm}^{2}$ while applying a current. It can be seen that the generation of cracks on the photoresist on the plating at higher temperatures is improved by increasing the

RESIST

COARTING

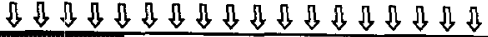

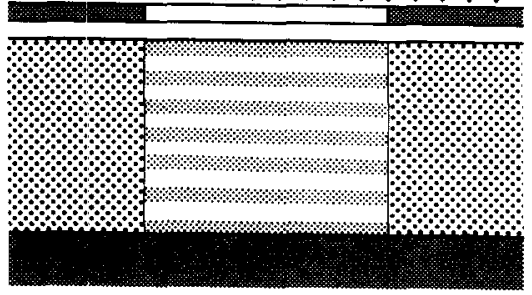

DEVELOPMENT

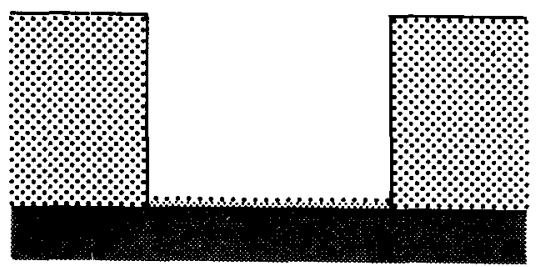

Fig. 6 Schematic mechanism of partilly developed case. $\mathbf{H}$, Un-decomposed NQD ester; 承, Partially decomposed NQD ester; $\square$, Completely decomposed NQD ester.

average molecular weight of the novolak resin in the resist. Conclusively, the plating is found to be accomplishable within half the period of time required in a conventional process, yet without the generation of cracks in the resist even under a current applied and at a density twice that used in the prior-art technology.

\section{CONCLUSION}

A positive photoresist with improved anticracked on the plating was thus achieved by removing the lower-molecular-weight fraction of the novolak resin from the resist. This enabled plating at a higher temperature of $70^{\circ} \mathrm{C}$ or even higher as compared with the conventional plating process of $60^{\circ} \mathrm{C}$, yet without generating any cracks even during high speed plating being 


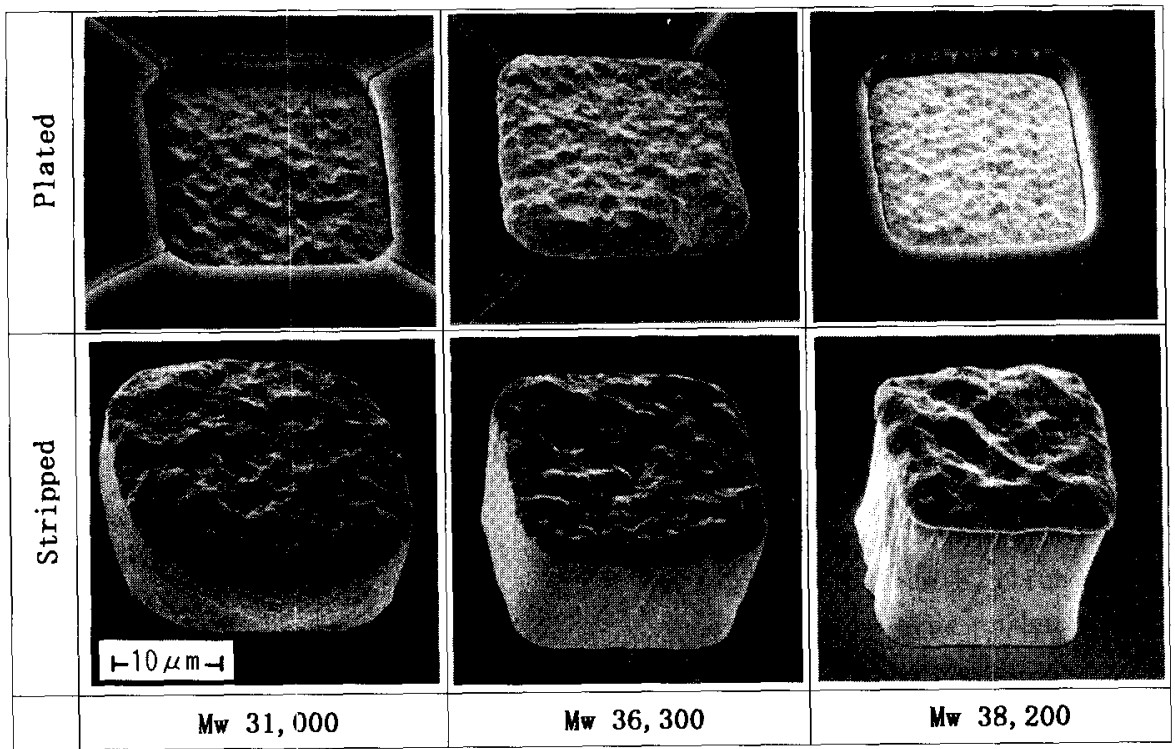

Fig. 7 High speed plated bump pattern; Current density, $0.8 \mathrm{~A} / \mathrm{dm}^{2}$; Temperature, $70^{\circ} \mathrm{C}$; Plating time, $30 \mathrm{~min}$.

effected by applying a current at a density twice as large as that conventionally used in the art. Thus, the time necessary for the plating was reduced to half of that required in the conventional process.

Profiles with vertical side walls were obtained in puddle development process by shortening the time period for each dipping, but by increasing the number of times the developer is replenished.

Fine bumps were implemented by forming straight bumps with vertical side walls. This was accomplished by using a positive photoresist containing a novolak resin consisting of higher-molecular-weight fractions alone and by employing the newly-improved development process.

\section{References}

1) K. Saito, Densizairyo, 1991-5, 25 (1991).

2) A. Todo, Nikkei New Material, 1991-12-25, 103 (1991).

3) H. Komano, Hyomen Gijutsu, 44, 490 (1993).

4) S. Asaumi, H. Nakane, J. Electrochem. Soc., 137, 2546 (1990).

5) S. Asaumi, M. Furuta, J. Electrochem. Soc., 139, 889 (1992). 